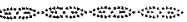 \\ Note
}

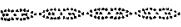

(Received July 1, 1996)

\section{Morphological Study on Polytetrafluoroethylene During the Crystallization Process at a Constant Cooling Rate from the Melt}

\section{Hiroshi Toyoda, Hiroshi Sakabe*t, Takashi Itoh, and Takashi Konishi}

Faculty of Textile Science, Kyoto Institute of Technology, Matsugasaki, Sakyo-ku, Kyoto, 606 Japan

\begin{abstract}
Polytetrafluoroethylene (PTFE) was slowly crystallized from the melt and quenched into ice water just when the sample reached a prescribed temperature ( $\mathrm{T}_{\mathrm{p}}$ ) to terminate the excess crystallization. The Tp-dependence of the surface morphology of PTFE was examined in a scanning electron microscope to find that thin bands ca. $120 \mathrm{~nm}$ wide appeared in the early stage of the crystallization and grew up with decreasing Tp finally to merge each other. The in situ observation by polarized light microscopy suggested that PTFE molecules lay parallel to the substrate.
\end{abstract}

\section{Introduction}

Several studies have been reported $[1-7]$ for the external surface structure of polytetrafluoroethylene (PTFE) as well as the fractured internal surface since morphological structure on the fractured surface of the melt crystallized PTFE was observed by electron microscopy to show that the fractured surface was covered with thick bands with fine longitudinal striations [8]. We reported the developing process of the bands observed on the fractured surface during slow cooling of the sample, being correlated with the sheaf-like bands on the external surface (9). From the viewpoint of practical use of the polymer, it seems to be important to study the structural development during the crystallization proces. ses at slow-cooling rates or the non-isothermal crystallization processes.

In this study, an apparatus is designed to quench the sample to $0{ }^{\circ} \mathrm{C}$ (ice water) from the prescribed final crystallization temperature ( $T p)$, to which the sample was cooled slowly from the melt. The Tp-dependence of the morphology on the external surface of the meltcrystallized PTFE was examined by scanning electron microscopy (SEM) as well as light microscopy (LM).

\section{Experimental}

The original sample was supplied by DuPont Company

\footnotetext{
* Present address: Yokohama Center for Quality Control and Consumer Service, Naka-ku, Yokohama, 231 Japan.
}

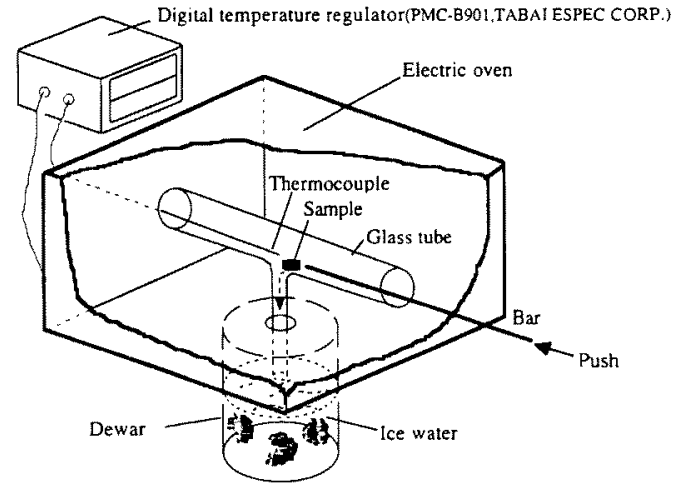

Fig. 1 A scheme of an apparatus which quenches the slow-cooled sample at Tp.

as an aqueous dispersion (TE-30J). An aluminum subs trate was immersed in the PTFE dispersion at room temperature and then withdrawn vertically to form the thin layer of PTFE on the substrate. After drying at 110 ${ }^{\circ} \mathrm{C}$, the layers or films of PTFE were so thin (thinner than $20 \mu \mathrm{m}$ ) that the heat transfer factor in the film was considered to be negligible. The sample was placed in an electric oven as shown in Fig. 1 to be held at 380 ${ }^{\circ} \mathrm{C}$ for $60 \mathrm{~min}$ and then cooled down at a rate of $0.5{ }^{\circ} \mathrm{C}$ /min to a prescribed temperature (Tp) between 250 and $380{ }^{\circ} \mathrm{C}$ (the melting point is $327^{\circ} \mathrm{C}$ ). The sample was dropped into ice water to terminate the crystallization just when the temperature became $T p$. This method fol lowed the ultra-quenching technique developed by Jones et al [10]. The samples were dried in air at room 


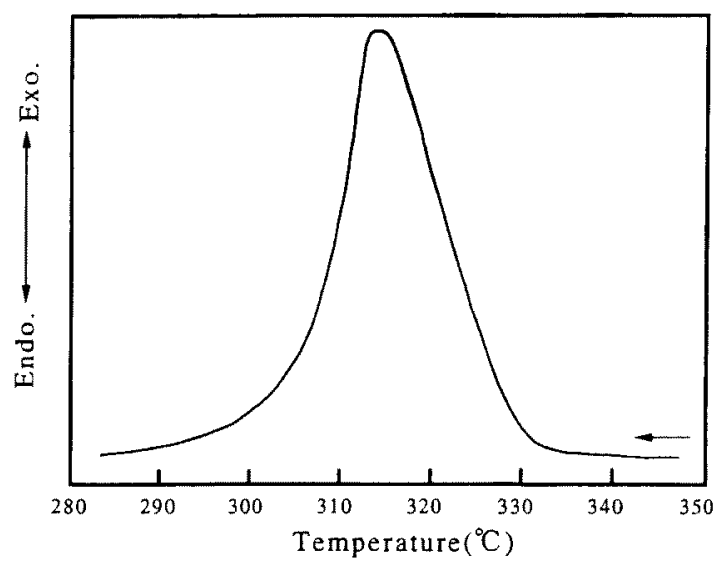

Fig. 2 A DSC thermogram of PTFE during cooling process from $380^{\circ} \mathrm{C}$ at $20^{\circ} \mathrm{C} / \mathrm{min}$.

temperature before the following experiments.

The external surface of the film was observed in a scanning electron microscope (SEM, JSM-5200LV) at an accelerating voltage of $15 \mathrm{kV}$ and at a viewing angle of $30^{\circ}$ after being coated with Au.

The thermal property of the sample was analyzed using a differential scanning calorimeter (DSC, Seiko, S. 220) at a scanning rate of $20^{\circ} \mathrm{C} / \mathrm{min}$ (or $-20^{\circ} \mathrm{C} / \mathrm{min}$ ).

One drop of the PTFE dispersion was applied onto a glass plate at room temperature only for light microsco. pic (LM) observation. After being dried, the sample was heated to $380{ }^{\circ} \mathrm{C}$ and kept for $60 \mathrm{~min}$ in a hot stage (Linkam, TM-600PM). The polarized light micrographs of the sample were taken at different temperatures dur ing the cooling process at a rate of $0.1{ }^{\circ} \mathrm{C} / \mathrm{min}$ from 380 to $200^{\circ} \mathrm{C}$ by Nikon Optiphot Pol with a color sensitive plate (retardation : $\mathrm{R}=530 \mathrm{~nm}$ )

\section{Results and Discussion}

A DSC thermogram on cooling $\left(20^{\circ} \mathrm{C} / \mathrm{min}\right)$ of PTFE as-dried from the original dispersion is shown in Fig. 2, which shows that the crystallization starts around 330 ${ }^{\circ} \mathrm{C}$ and a single exothermic peak is observed at $313^{\circ} \mathrm{C}$.

The degree of crystallinity of the PTFE thin film peeled from the aluminum substrate was estimated from the heat of fusion assuming that the heat of fusion of the PTFE crystal is $14.6 \mathrm{cal} / \mathrm{g}[11.12]$. The Tp-dependence of the degree of crystallinity for the slow-cooled PTFE from the melt is shown in Fig. 3, which apparently indi. cates development of the crystallinity of PTFE from 30

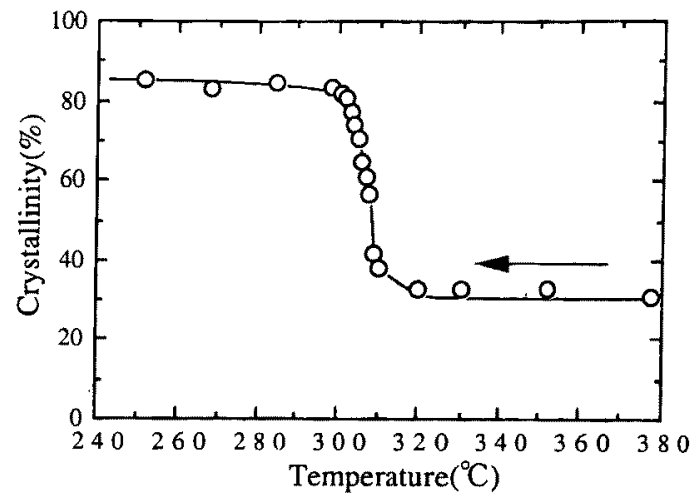

Fig. 3 The Tp-dependence of the degree of crystallinity of PTFE slow-cooled and quenched into ice water from the melt.

to $85 \%$ with decreasing $\mathrm{Tp}$ especially between 320 and $300{ }^{\circ} \mathrm{C}$

A series of SEM photographs for the external surface of the slow-cooled PTFE with different $\mathrm{Tp}$ are shown in Figs. 4(a)-(f). Any characteristic crystallization feature is not observed on the smooth surface of the quenched film from $330^{\circ} \mathrm{C}$ as shown in Fig. 4 (a), while a band appears when the sample is quenched from $315{ }^{\circ} \mathrm{C}$ (note a white striation pointed by an arrow in Fig. 4 (b), which corresponds to the protruded region caused by the sheaflike band formation). The number and size of the band increase with decreasing $T p$ as shown in Figs. 4(c)-(f).

In situ observation on PTFE during the cooling process from $380^{\circ} \mathrm{C}$ was also performed by polarized light microscopy. The results are shown in Figs. $5(a) \cdot(d)$. Any characteristic fine structure is not observed in Fig. $5(\mathrm{a})$, taken at $380^{\circ} \mathrm{C}$. The optically anisotropic or biref. ringent regions are observed in Fig. 5 (b), which sug gests that crystallization starts even at $330^{\circ} \mathrm{C}$ nevertheless any band was not observed by SEM on the external surface for the quenched film from $330^{\circ} \mathrm{C}(\mathrm{Tp})$. It is shown from Figs. $5(\mathrm{c}) \cdot(\mathrm{d})$ that the number and size of crystalline regions of PTFE increase during the cooling process. Such birefringent feature in the crystalline re gion suggests that PTFE molecules lie parallel to the substrate surface because the refractive indices in the directions along the $\mathrm{a}$ - and $\mathrm{b}$-axes are considered to be almost the same in the high-temperature pseudohexagonal phase (phase I) $[13,14]$ and the refractive index in the direction along the c-axis (chain axis) is greater than 


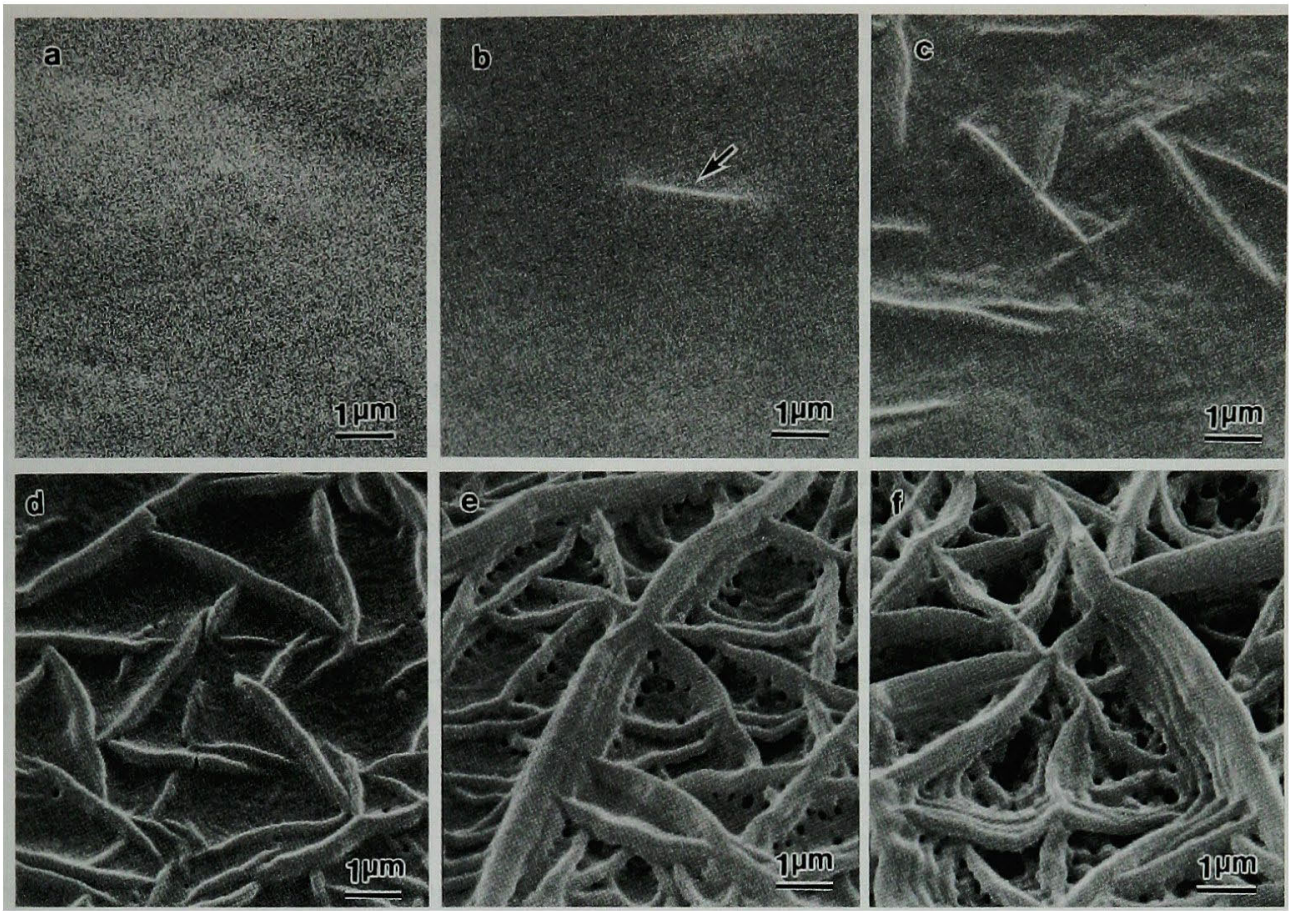

Fig. 4 SEM photographs of the external surfaces of PTFE which were slow-cooled from the melt and quenched into ice water form a variety of $\mathrm{Tp}$; (a) $330{ }^{\circ} \mathrm{C}$, (b) $315{ }^{\circ} \mathrm{C}$, (c) $312{ }^{\circ} \mathrm{C}$, (d) $310{ }^{\circ} \mathrm{C}$, (e) $304{ }^{\circ} \mathrm{C}$, and (f) $280{ }^{\circ} \mathrm{C}$.
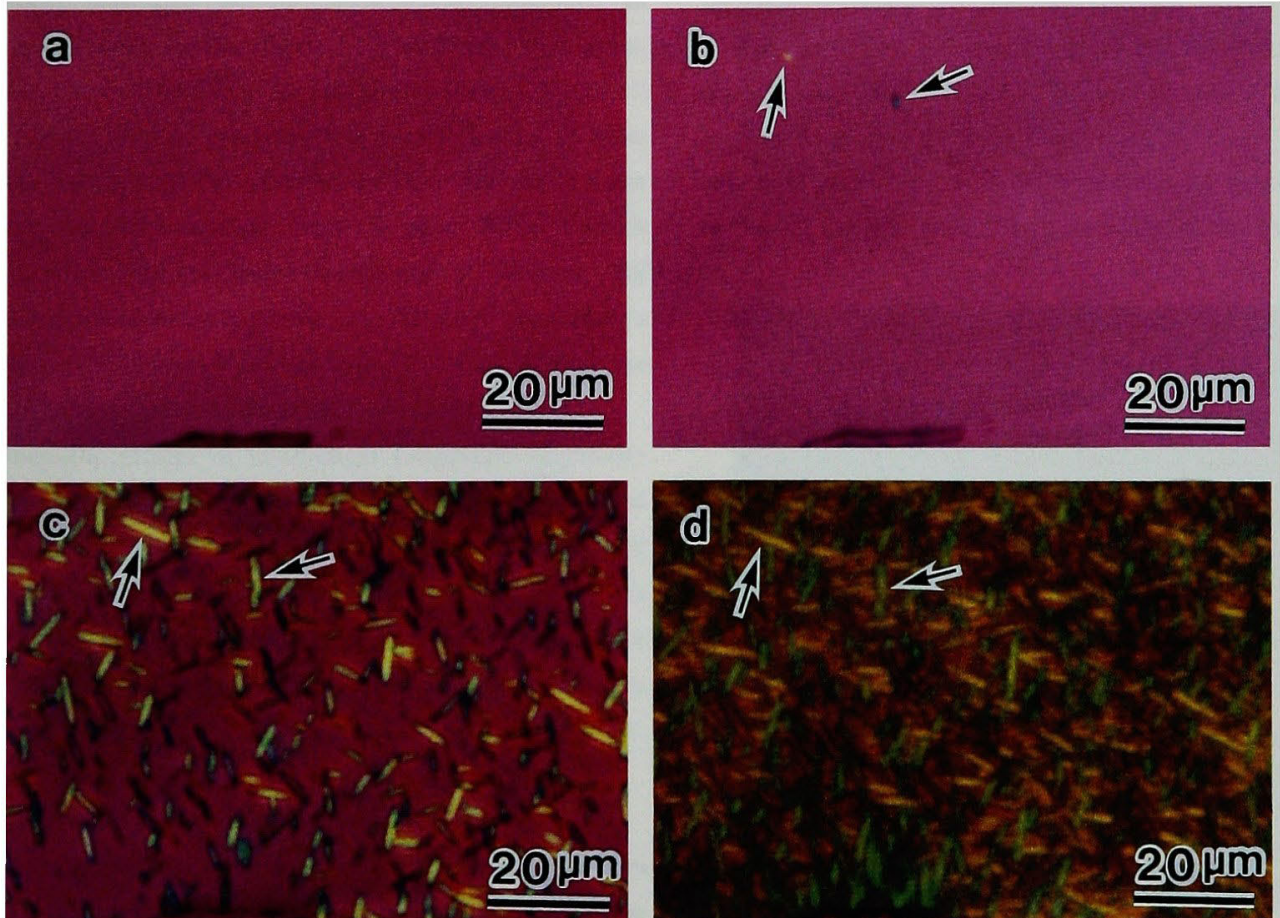

Fig. 5 In-situ-observed polarized LM-photographs during the cooling process from $380{ }^{\circ} \mathrm{C}$. The observed temperatures are (a) $380{ }^{\circ} \mathrm{C}$, (b) $330{ }^{\circ} \mathrm{C}$, (c) $320{ }^{\circ} \mathrm{C}$, and (d) $280{ }^{\circ} \mathrm{C}$. 
the others. This is consistent with the report [7] suggesting that the higher refractive index is in the direction perpendicular to the long axis of the band.

\section{References}

1. P. E. Thomas, J. F. Lontz, C. A. Sperati, and J. L. McPherson. J. Soc. Plast. Eng.. 12, 89 (1956).

2. T.Y. Hu and N. S. Eiss, Jr., Wear, 84, 203 (1983).

3. C. J. Speerschneider and C. H. Li, J. Appl. Phys., 33, 1871 (1962).

4. H. W. Starkweather, Jr., SPE Transaction, 57 (1963).

5. S. Yamaguchi, Kobunshi Ronbunshu, 39, 493 (1982).

6. S. Yamaguchi, Kobunshi Rombunshu, 41, 755 (1984).

7. N. K. J. Symons, J. Polym. Sci., A-1, 2843 (1963).
8. C. W. Bunn, A. J. Cobbold, and R. P. Palmer, J. Polym. Sci., 28, 365 (1958)

9. H. Toyoda, H. Sakabe, T. Itoh, and T. Konishi, Sen'i Gakkaishi, 51, 559 (1995).

10. J. B. Jones, S. Barenberg, and P. H. Geil, Polymer, 20, 903 (1979).

11. P. L. Mcgeer and H. C. Duus, J. Chem. Phys., 20, 1813 (1952).

12. T.Y. Hu, Wear, 82, 369 (1982).

13. P. Corradini and G. Guerra, Macromolecules, 10, 1410 (1977).

14. P. H. Geil, "Polymer Single Crystals", John Wiley \& Sons Inc., New York, p.301 (1973). 